\title{
UNIVERSITIES IN THE MARKETPLACE: THE COMMERCIALIZATION OF HIGHER EDUCATION
}

\author{
Por Gilmar Masiero \\ Professor da Universidade Estadual de Maringá \\ E-mail: g_masiero@yahoo.com
}

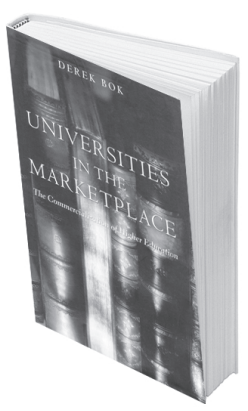

\section{UNIVERSITIES IN THE MARKETPLACE: THE COMMERCIALIZATION OF HIGHER EDUCATION}

De Derek Bok

Princeton and Oxford : Princeton University Press, 2003. 233p.

Nos últimos 20 anos, universidades têm mudado seu tradicional foco de formação para cada vez mais enfatizar ensino e pesquisas multidisciplinares estreitamente relacionadas com finalidades práticas e comerciais. $\mathrm{Na}$ academia surgem questionamentos acerca dessas mudanças e manifestações preocupadas com a crescente tendência de administrar as atividades universitárias sob o princípio empresarial, de alocação e gestão de recursos baseado no lucro. Universities in the marketplace, de Derek Bok, expresidente da Universidade de Harvard (1971-91), é uma oportuna contribuição ao debate.

As preocupações do autor, conhecido também pelo lema "se você pensa que educação é cara, experimente a ignorância", estão expressas no prefácio do livro, no qual afirma que as universidades "têm estado muito mais agressivas do que antigamente em tentar ganhar dinheiro de suas atividades de ensino e pesquisa. Muitas instituições têm lançado [...] uma variada gama de iniciativas comerciais". Bok deixa clara sua inquietação sobre o fato de a recente tendência mudar o caráter acadêmico das instituições de ensino superior e comprometer seus essenciais valores de continuada confiança e lealdade para com os professores, os estudantes e o público em geral. Contra essas tendências, ele recomenda a adoção de "apropriadas políticas" para limitar seus aspectos negativos.

Segundo Bok, o início da comercialização nas universidades data dos princípios do século XX, o autor menciona as idéias de Thorstein Veblen (1918), os anúncios da Universidade de Chicago para atrair estudantes nos primeiros anos do século e a contratação de um treinador de 26 anos de idade, com um salário igual ao do presidente da Universidade de Harvard em 1905, para mostrar que as atividades comerciais no interior das universidades não são um fenômeno recente. Entretanto, tais tendências cresceram significativamente depois da Segunda Guerra Mundial e com muito mais força depois da Lei Bayh-Dole (1980) que permitiu que as universidades possuíssem a propriedade e licenciassem patentes de inovações desenvolvidas a partir do fomento público de suas atividades. Nos Estados Unidos, a colaboração entre as universidades e as empresas gerou sucessos comerciais, como o Vale do Silício, o Triângulo de Pesquisa, o Milagre de Austin e a Rota 128.

A comercialização no interior das universidades, em muitos casos liderada pelas business schools, é refletida em uma série de tendências, em que se percebe: 1) a influência das forças 
econômicas sobre a universidade (como o crescimento das ciências da computação); 2) a pressão da cultura corporativa (por exemplo, o extensivo uso de termos como "marca", "trade-offs" e "custo-benefício"); 3) o poder dos estudantes sobre o currículo (como mais cursos vocacionais); 4) os esforços de redução de custos e despesas ou utilização de métodos administrativos adaptados do mundo empresarial (como a contratação de professores em tempo parcial e os programas de qualidade total); ou, ainda, 5) a tentativa de quantificar numericamente atividades acadêmicas sem considerar seus aspectos qualitativos. Paralelamente a essas tendências, é também crescente o número de parcerias universidades-empresas, visando ao desenvolvimento conjunto de ensino, pesquisa, educação continuada e gerenciamento de incubadoras de negócios.

Após diagnosticar a incorporação de princípios provenientes do setor empresarial nas múltiplas atividades universitárias, Bok parece justificá-los por meio de outro princípio comum do mundo dos negócios - a competição. Baseado nela, descreve a crescente comercialização do ensino, das práticas esportivas, da pesquisa e de outras atividades acadêmicas que colocam em risco a reputação de estudantes, professores e o próprio papel da universidade frente à sociedade $\mathrm{em}$ geral. De forma mais prescritiva, segue sugerindo, na segunda metade do livro, uma melhor e mais eqüitativa distribuição dos milionários recursos da Divisão I de Futebol entre outros esportes e demais divisões, bem como o estabelecimento de políticas que priorizem a melhoria do ensino dos estudantes-atletas. Visando a não comprometer a abertura, a objetividade e a independência da pesquisa acadêmica, segredos e conflitos de interesse, segundo ele, devem ser ad- ministrados pelo estabelecimento de regras claras e reduzida dependência da indústria.

Apesar de acreditar em "políticas apropriadas" para conter a crescente comercialização das atividades acadêmicas, Bok, reconhece que nos esportes e na educação continuada de médicos, em que a presença dos laboratórios farmacêuticos é predominante, é difícil reverter a tendência. A busca de "políticas apropriadas" está presente também em um relatório publicado pela Universidade de Harvard em 1945 - no "livro vermelho" denominado General education in a free society. O relatório mencionado por Eric Gould (2003) em The university in a corporate culture levanta um importante dilema a ser enfrentado pela educação superior ao afirmar que "lutamos pela implementação de um currículo de graduação que ressalta um racionalizado conjunto de conhecimentos que cobre a 'natureza da realidade' e outro que enfatiza processos de aprendizagem mais pragmáticos; currículos indutivos que favorecem learning by doing". A batalha entre os que acreditam no conhecimento como um meio de alcançar objetivos (ciência aplicada) e os que o pensam como um fim em si mesmo (ciência pura) parece ser interminável.

Em Universities in the marketplace, Bok apresenta uma útil descrição das tensões desses dilemas e recomenda o equilíbrio das mesmas. Todavia, existem tendências no mercado norte-americano de educação superior que não foram consideradas nas argumentações sobre a excessiva comercialização nas universidades. Os apelos do livro seriam mais convincentes se o autor tivesse providenciado informações sobre como a produção e a disseminação do conhecimento causam impacto no crescente aumento dos preços da educação, da ajuda financeira e dos subsídios universitários. Além disso, o autor não considera como tais tendências influenciam o também crescente gap entre universidades ricas e pobres de recursos.

Ao longo da história, as universidades parecem ter mais respondido a seus agentes de fomento do que exercido sua livre e autônoma vontade. Uma possível hipótese sobre a evolução das forças que influenciaram o desenvolvimento das universidades nos últimos cinco séculos pode ser a que conduziu suas atividades pelos lemas "reze ou padeça", "publique ou padeça", "patenteie ou padeça" e, mais atualmente, "comercialize ou padeça". Na evolução da criação e disseminação do conhecimento, quando os fomentadores da atividade científica foram as instituições religiosas, o lema "reze ou padeça" parece ter sido o princípio orientador. Nos casos em que o principal agente investidor foram as indústrias, "comercialize ou padeça" tem predominado como princípio orientador da produção do conhecimento.

O sucesso de uma universidade depende de sua habilidade em combinar os ideais da racionalidade cognitiva, a responsabilidade social e os valores culturais com os sistemas políticos e econômicos. Para enfrentar esse desafio, as instituições de ensino superior devem adotar uma perspectiva global e histórica de seu papel institucional - o de enfatizar a cooperação em vez da competição (reificada no livro de Bok). Se as universidades se deixarem regular pelas regras competitivas do mercado, cedo ou tarde, a exemplo das empresas, perecerão. Para que seja possível reduzir as tensas relações éticas e teóricas entre nós - pregadores, professores, pesquisadores e comerciantes -, a cooperação, em vez da competição, deve ser o princípio básico, como meio e fim em si mesmo, de toda atividade científica. 